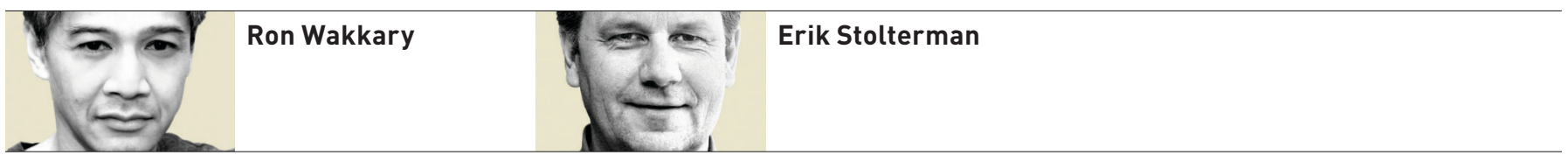

\title{
HCI and the Future
}

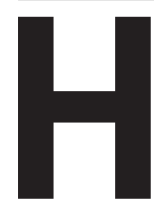

$\mathrm{CI}$ is an area that is to some extent obsessed with the future. We research and design technological solutions that do not yet exist. And the field is always looking for what is new and novel. Even our research conferences have sessions where the focus is on what is new-on new designs, on the next step in the evolution of interactivity, and so on. In the cover story, Bonnie Nardi explores a question related to this fixation on the future. She asks, "Which future?" Will the future be the one we want or the one that is inevitable and not necessarily desired?

It is not only a question of which future; it is maybe even more a question of how to explore the future. Should we try to predict, should we speculate, and in what way should we engage in the construction of the future? Nardi examines these questions in several ways and concludes with some advice: "There is something important to be taken from varied, concrete engagements with the future, whether the most delicately designed technocentric experiments of material speculation, or broadly informed analyses of the vast complexities of history and political economy. The more deeply we investigate all of the possibilities, the more prepared we will be to design for whichever futures come along."

In this issue we also present a Special Topic with articles from the Communities and Technologies conference. The section contains three articles that the conference audience chose based on the authors' presentations. Together these articles give an overview of some of the core themes in this research community. We thank Volkmar Pipek, Gabriela Avram, and Fiorella De Cindo for the work they have done to make this Special Topic possible and for writing the introduction.

We also continue a new section that debuted last issue. In each issue we will publish a post by one of our bloggers that has attracted a lot of readers. We see this as a way of rewarding our bloggers but also of showing the readers of our print magazine that there are more stories on our website (http://interactions.acm.org/).

Remember, we are always looking for new and exciting pieces. We know you have ideas and opinions that should be shared, so just get in touch with us!

Ron Wakkary and Erik Stolterman eic@interactions.acm.org

\section{It is not only a question of which future; it is maybe even more a question of how to explore the future.}

